\title{
Quantitative Distribution of the Glycine Receptor in the Auditory Brain Stem of the Gerbil
}

\author{
Dan H. Sanes, William A. Geary, G. Frederick Wooten, and Edwin W Rubel ${ }^{2}$ \\ Departments of Neuroscience, Physiology, Otolaryngology, and Neurology, University of Virginia Medical Center, \\ Charlottesville, Virginia 22908
}

\begin{abstract}
The concentration and relative distribution of glycine receptors were determined for gerbil brain stem auditory nuclei using ${ }^{3} \mathrm{H}$-strychnine and quantitative autoradiographic techniques. Significant binding was observed in the anteroventral cochlear nucleus, the dorsal cochlear nucleus, the lateral superior olivary nucleus, and the inferior colliculus. A nonuniform distribution of binding was seen in 3 of these nuclei, such that the greatest concentration of glycine receptors was located in the high-frequency regions. An analysis of neuron soma density suggested that the amount of postsynaptic membrane could partially explain the distribution of receptor.
\end{abstract}

There is both physiological and autoradiographic evidence that glycinergic synapses arc present in brain stcm auditory nuclei. Iontophoretic application of glycine suppresses tone-evoked activity in the dorsal cochlear nucleus (DCN) and the lateral superior olivary nucleus (LSO), while strychnine antagonizes both the glycine effect and tone-evoked inhibition (Moore and Caspary, 1983; Caspary et al., 1985). Tritium-labeled glycine has been localized to synaptic terminals within both DCN and LSO (Schwartz, 1985). The ultrastructure of these terminals was similar to those thought to be inhibitory endings. The immunocytochemical localization of monoclonal antibodies directed against the glycine receptor has been found for DCN, LSO, the medial superior olivary nucleus, the anteroventral cochlear nucleus (AVCN), and the medial nucleus of the trapezoid body (Wenthold et al., 1985; D. H. Sanes and H. Betz, unpublished observations). Finally, a monoclonal antibody directed against conjugated glycine strongly labels the cell population thought to provide the inhibitory projection onto the LSO, the medial nucleus of the trapezoid body (Campistron et al., 1986).

The present study employs the glycine receptor antagonist, strychnine. The high binding affinity of strychnine (SN), an alkaloid, for the glycine receptor has been well-established (Curtis et al., 1971; Young and Snyder, 1973; Snyder, 1975; Zarbin et al., 1981). Recently, this characteristic has contributed to the

Received Dec. 17, 1986; revised May 14, 1987; accepted May 20, 1987.

This work was supported by National Institutes of Health Grants NS 15478 (E.W.R.), NS 07462 (D.H.S.), and DA 03787 (G.F.W. and W.A.G.) as well as by the Mary Anderson Harrison Endowment of the University of Virginia. We wish to thank Rose Powell for the preparation of the manuscript.

Correspondence should be addressed to Dan H. Sanes, Departments of Otolaryngology and Physiology and Biophysics, NYU Medical Center, 550 First Ave., New York, NY 10016.

- Present address: Department of Otolaryngology, RL-30, University of Washington, Seattle, WA 98195.

Copyright (C) 1987 Society for Neuroscience $0270-6474 / 87 / 113793-10 \$ 02.00 / 0$ purification and partial characterization of the glycine receptor (Pfeiffer and Betz, 1981; Pfeiffer et al., 1982). Competition experiments had previously shown $\mathrm{SN}$ to be a quite specific ligand (Young and Snyder, 1973; Zarbin et al., 1981); in addition, the binding pattern in brain of monoclonal antibodies directed against the purified glycine receptor is similar to that of ${ }^{3} \mathrm{H}-\mathrm{SN}$ (Hosli and Hosli, 1981; Triller et al., 1985).

Since the present study was directed at ascertaining both the absolute concentration of glycine receptor and the relative concentration within a nucleus, a major methodological concern was finding a reproducible means of calibrating the densitometric readings obtained from the autoradiographic images. Geary et al. (1985) have demonstrated the feasibility of using tritium-impregnated plastic standards for this purpose. In addition, these authors point out the necessity of quantifying the autoabsorption of the tritium signal for each tissue of interest. A simple and reproducible method involves the chloroform extraction of alternate sections of tissue that have previously incorporated ${ }^{3} \mathrm{H}-2$-deoxyglucose and a comparison of the autoradiographic images generated by these pairs of sections (Geary et al., 1985).

The present study was conducted in conjunction with an electrophysiological analysis of inhibition within the LSO (Sanes and Rubel, in press) and a study of the ontogenetic appearance and localization of the receptor molecule (Sanes and Wooten, 1987).

\section{Materials and Methods}

Tissue preparation. Male and female gerbils (Meriones unguiculatus) raised in our breeding colony for 12-17 weeks were first anesthetized with sodium pentabarbitol $(60 \mathrm{mg} / \mathrm{kg}$, i.p.) and decapitated. The brains were rapidly removed from the skull and immersed in liquid Freon for $30 \mathrm{sec}$. The frozen tissue was then either stored at $-80^{\circ} \mathrm{C}$ for subsequent use or immediately mounted for cryostat sectioning. Serial $20 \mu \mathrm{m}$ sections were cut at $-16^{\circ} \mathrm{C}$, thaw-mounted onto gelatin-coated coverslips and immediately refrozen within the cryostat (American Optical). Sections were stored for no more than $6 \mathrm{~d}$ at $-35^{\circ} \mathrm{C}$ before use. Sections were brought to room temperature for $40 \mathrm{~min}$ prior to each binding experiment.

Kinetic and competition analyses. All sections used for kinctic analyses were taken from that region of the brain stem containing the superior olive. The sections were first preincubated in PBS $\left(20 \mathrm{mM} \mathrm{Na} 2 \mathrm{HPO}_{4}\right.$, $2 \mathrm{mM} \mathrm{NaH}_{2} \mathrm{PO}_{4}, 150 \mathrm{~mm} \mathrm{NaCl}, \mathrm{pH} 7.4$ ) for $20 \mathrm{~min}$, allowing endogenous ligand (e.g., glycine) to dissociate. This and all other solutions were kept at $4^{\circ} \mathrm{C}$. The rate of strychnine (SN) association to receptor was examined by incubating sequential tissue sections in $10 \mathrm{nM}^{3} \mathrm{H}-\mathrm{SN}$ (New England Nuclear; $26.7 \mathrm{Ci} / \mathrm{mmol}$ ) for $0.5,2,5,10,20,40$, and 60 $\mathrm{min}$. In this and subsequent experiments, alternate sections were incubated in radiolabeled ligand with $10^{-2} \mathrm{M}$ glycine added to determine nonspecific binding. After incubation with ligand, sections were rinsed for $10 \mathrm{sec}$ in PBS, dipped in $\mathrm{dH}_{2} \mathrm{O}$, and rapidly air-dried. The rate of dissociation was determined in similar fashion except that sections were 


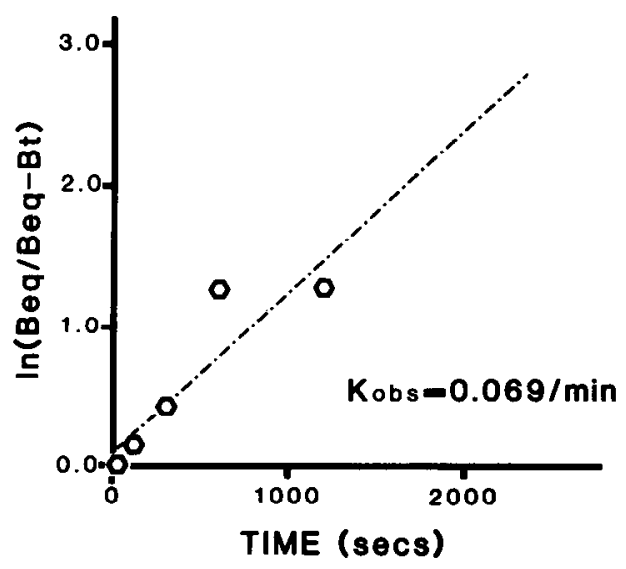

Figure 1. Association binding kinetics. An analysis of the time course of association of ${ }^{3} \mathrm{H}-\mathrm{SN}$ to slide-mounted tissue sections for specific binding is shown. The slope of the line $K_{\mathrm{obs}}$ is indicated.

incubated for $20 \mathrm{~min}$ in ligand and then rinsed for $0.17,0.5,1,2,5$, 10, and $30 \mathrm{~min}$ in PBS. The air-dried sections obtained in each experiment were solubilized in $15 \mathrm{ml}$ of Formula 947 scintillation cocktail (New England Nuclear) and counted by scintillation spectroscopy.

The saturation kinetics were ascertained by incubating sections in 1 , $2,5,10$, and $15 \mathrm{nM}{ }^{3} \mathrm{H}-\mathrm{SN}$ for $20 \mathrm{~min}$. The sections were then rinsed for 10 sec in PBS, dipped in $\mathrm{dH}_{2} \mathrm{O}$, air-dried and counted by scintillation spectroscopy. Data obtained from this experiment were analyzed by Eadie-Hofstee and Hill plots. Quantitative estimates of $K_{\mathrm{d}}( \pm \mathrm{SE})$ and $B_{\max }( \pm \mathrm{SE})$ were calculated according to Zivin and Waud (1982).

The specificity of SN binding was determined by competing 3 unlabeled amino acids (i.e., glycine, $\gamma$-aminobutyric acid, and glutamate) with $10 \mathrm{nM}{ }^{3} \mathrm{H}-\mathrm{SN}$. All amino acids were used at concentrations of $10^{-2}$, $10^{-3}$, and $10^{-4} \mathrm{M}$, and glycine was also used at $10^{-5} \mathrm{M}$. Adjacent alternating sections were used for all concentrations of labeled and unlabeled ligand tested.

Autoabsorption. The extent to which tissue prevented the tritium signal from reaching LKB film was determined. Animals were injected intraperitoneally with $250 \mu \mathrm{Ci}$ of ${ }^{3} \mathrm{H}$-2-deoxy-D-glucose (New England Nuclear; $30.2 \mathrm{Ci} / \mathrm{mmol}$ ). Following a $45 \mathrm{~min}$ survival period, animals werc anesthetized, decapitated, and the brain rapidly removed and frozen. Cryostat sections through the cochlear nucleus, superior olive, and inferior colliculus (ICC) were mounted on coverslips and air-dried. Alternate sections were extracted in $500 \mathrm{ml}$ of chloroform for $5 \mathrm{~min}$ at room temperature. All sections were apposed to LKB Ultrafilm (Kodak) for 4 weeks and subjected to densitometric analysis. The sections were also counted by scintillation spectroscopy to ensure that counts were not lost in the chloroform (data not shown). This procedure has previously been shown to provide accurate estimates of autoabsorption (Geary et al., 1985).

Quantitative autoradiography. Tissue sections to be used for autoradiographic determination of glycine receptor concentration were incubated in $10 \mathrm{~nm}{ }^{3} \mathrm{H}-\mathrm{SN}$ for $20 \mathrm{~min}$, rinsed in PBS for $5 \mathrm{sec}$, dipped in $\mathrm{dH}_{2} \mathrm{O}$, and rapidly air-dried. After apposition to LKB Ultrafilm for 4 wecks, densitometric analyses were performed on a Leitz MPV Microdot Densitometer with an adjustable aperture. In addition to the tissue sections, each film was exposed to calibrated tritium-containing plastic standards (Amersham). Thus, a specific optical density (OD) measurement was equivalent to a value expressed as $\mathrm{nCi} / \mathrm{mg}$ of tissue wet weight (Geary et al., 1985). A final concentration was computed by multiplying this quantity by the inverse of the specitic activity of the ligand:

$$
\frac{X \mathrm{nCi}}{\mathrm{mg} \text { wet weight }} \cdot \frac{\mathrm{fmol}}{V \mathrm{nCi}}=\frac{\mathrm{fmol}}{\mathrm{mg} \text { wet weight }} .
$$

The ODs obtained from sections incubated in the presence of $10^{2} \mathrm{M}$ glycine were subtracted from the ODs of sections incubated in ${ }^{3} \mathrm{H}-\mathrm{SN}$ alone to yield values for specific binding.

Cell soma density. The density of neurons was determined within several nuclei using Nissl-stained paraffin sections. Animals were anesthetized with pentabarbitol, perfused intracardially with $10 \%$ buffered formalin, and the brain removed. The brains were embedded in paraffin

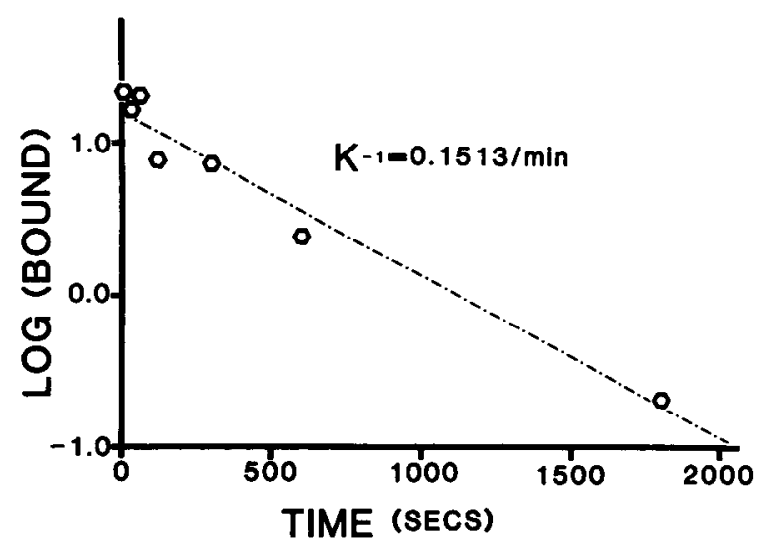

Figure 2. Dissociation binding kinetics. An analysis of the time course of dissociation of ${ }^{3} \mathrm{H}-\mathrm{SN}$ to slide-mounted tissue sections for specific binding is shown. The rate constant for the reverse reaction, $k_{-1}$, is indicated.

and $8 \mu \mathrm{m}$ sections cut. A 1 -in- 4 series was mounted and stained in $1 \%$ thionin. Soma counts were obtained by visualizing the region of interest with a video camera (Dage 68) mounted on a compound microscope. The slides were examined at $40 \times$. The displayed image was analyzed using a Zeiss videoplan, with counts per unit area computed and averaged across sections. Only cells with nucleoli were counted.

\section{Results}

\section{Kinetics and specificity of strychnine}

We first determined the kinetic characteristics associated with the strychnine binding receptor in slide-mounted frozen tissue sections. These studies provided the incubation parameters that were subsequently used to ensure steady-state conditions. The time course of the association of ${ }^{3} \mathrm{H}-\mathrm{SN}$ with its receptor at $4^{\circ} \mathrm{C}$ was predominantly the first $20 \mathrm{~min}$; it began to asymptote after this point. An analysis of the association binding kinetics yielded a $K_{\text {obs }}=0.069 / \mathrm{min}$ (Fig. 1; triplicate sections for 3 animals for each time point). The dissociation of ${ }^{3} \mathrm{H}-\mathrm{SN}$ occurred rapidly over the first few minutes, asymptoting by approximately $5 \mathrm{~min}$. An analysis of the dissociation kinetics yielded a $k_{-1}=0.1513 /$ min (Fig. 2; triplicate sections from 3 animals for each time point). Using the values generated in the association and dissociation experiments, a dissociation constant $\left(K_{\mathrm{d}}\right)$ of $17.9 \mathrm{nM}$ was computed.

The saturation curve and a corresponding Eadie-Hofstee plot for ${ }^{3} \mathrm{H}-\mathrm{SN}$ binding are shown in Figures 3 and 4, respectively (triplicate sections from 4 animals for each concentration). The specific binding of ${ }^{3} \mathrm{H}-\mathrm{SN}$ appears to be maximal at concentrations above $15 \mathrm{~nm}$ (Fig. 3). The Eadie-Hofstee plot gave a calculated $K_{\mathrm{d}}$ of $15.9 \mathrm{nM}$ (Fig. 4), in close agreement with that calculated from the association and dissociation kinetics. The $B_{\max }$ was computed to be $47.5 \mathrm{fmol} /$ section.

The specificity of ${ }^{3} \mathrm{H}-\mathrm{SN}$ binding was assayed by competing this ligand with increasing concentrations of 3 unlabeled amino acids: glycine, GABA, and L-glutamate (triplicate sections from 3 animals for each concentration). As shown in Figure 5, glycine was by far the most potent antagonist, displacing approximately $70 \%$ of specific binding at a concentration of $10^{-4} \mathrm{M}$. Both L-glutamatc and GABA wcre relatively ineffective, displacing only $30 \%$ of specific binding even at a concentration of $10^{-2} \mathrm{M}$.

\section{Autoabsorption}

Potential differences between tissue densities of gray and white matter, leading to differences in the autoabsorption of tritium 


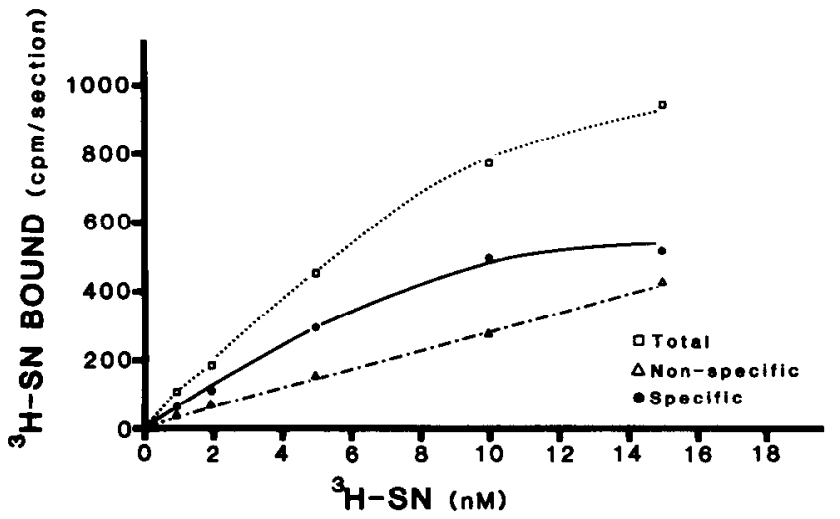

Figure 3. Saturation curve for ${ }^{3} \mathrm{H}-\mathrm{SN}$ binding in the brain stem at the level of the superior olivary nuclei. Specific binding is obtained by subtracting nonspecific binding (i.e., binding in the presence of $10^{-2} \mathrm{M}$ glycine) from total binding.

emissions, were corrected for within relevant auditory structures (see Materials and Methods). A summary of the regional autoabsorption values obtained is given in Table 1 . As there were no obvious regional differences in autoabsorption within AVCN, LSO, or ICC, the values were pooled within each nucleus prior to being employed as a correction factor when obtaining the concentration of glycine receptors.

\section{Quantitative autoradiography}

The autoradiographic images generated by ${ }^{3} \mathrm{H}-\mathrm{SN}$ bound sections indicated that the glycine receptor was present in all nuclei examined. Figure 6 shows representative total and nonspecific images of LSO, along with the corresponding cresyl-stained section. It is apparent from the total-binding image that a higher concentration of receptor is present in the dorsomedial region of LSO than in the ventrolateral region. The same kind of nonuniform distribution of binding was also observed in AVCN and ICC (Figs. 7, 8). In the case of AVCN, there is greater binding in the dorsal aspect of the nucleus, whereas in ICC there is greater binding in the ventral portion of the nucleus. In DCN

Table 1. Amount of autoabsorption within the brain stem auditory nuclei examined

\begin{tabular}{cll} 
& $\begin{array}{l}\text { Autoabsorption } \\
(\%)^{a}\end{array}$ & $\begin{array}{l}\text { No. of readings } \\
\text { (animals) }\end{array}$ \\
\hline DNC & 33 & $44(3)$ \\
PVCN & 48 & $42(3)$ \\
AVCN & & $(3)$ \\
Dorsal & 34 & 20 \\
Middle & 39 & 20 \\
Ventral & 36 & 20 \\
LSO & & 20 \\
Dorsal & 36 & 20 \\
Ventral & 39 & 20 \\
ICC & & $(3)$ \\
Dorsal & 34 & 18 \\
Middle & 36 & 18 \\
Ventral & 36 & 18
\end{tabular}

${ }^{a}$ All entries were computed from the ratio between signal in chloroform extracted and unextracted tissue sections (see Materials and Methods).

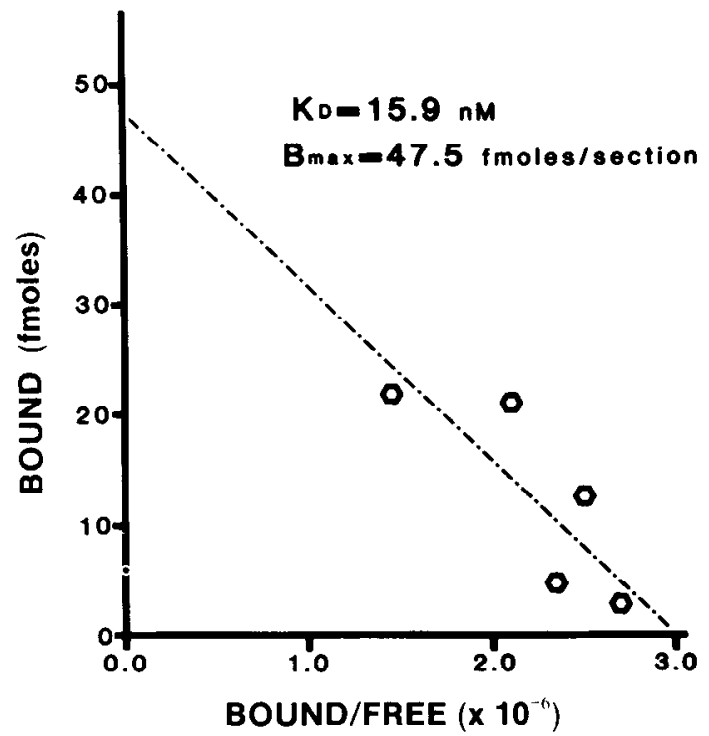

Figure 4. Eadie-Hofstee plot of ${ }^{3} \mathrm{H}-\mathrm{SN}$ binding in the brain stem at the level of the superior olivary nuclei. The $K_{\mathrm{d}}$ and $B_{\max }$, calculated from this graph, are shown.

and PVCN, the binding appears uniform, being much greater in the former (Fig. 9).

The receptor density was quantified using densitometric readings of total and nonspecific sections through each of these nuclei (see Materials and Methods). The measurements were made in distinct regions of AVCN, LSO, and ICC to document the extent of inhomogeneous binding. The concentrations of glycine receptor in each nucleus, corrected for autoabsorption, are given in Table 2. The DCN contained the highest concentration of rcceptor, at $465.5 \mathrm{fmol} / \mathrm{mg}$ tissue wet weight. The AVCN contained low levels of receptor ventrally $(154.8 \mathrm{fmol} / \mathrm{mg}$ wet weight), with an approximately 2.5 -fold increase dorsally $(390.4$ $\mathrm{fmol} / \mathrm{mg}$ wet weight). It should be noted that the inhomogeneity was far less in evidence within the rostral portion of AVCN, where the nucleus becomes more oblate. The PVCN contained a very low concentration of receptor at $105.1 \mathrm{fmol} / \mathrm{mg}$ wet weight.

The LSO was of particular interest in the present study because of correlative developmental and physiological studies

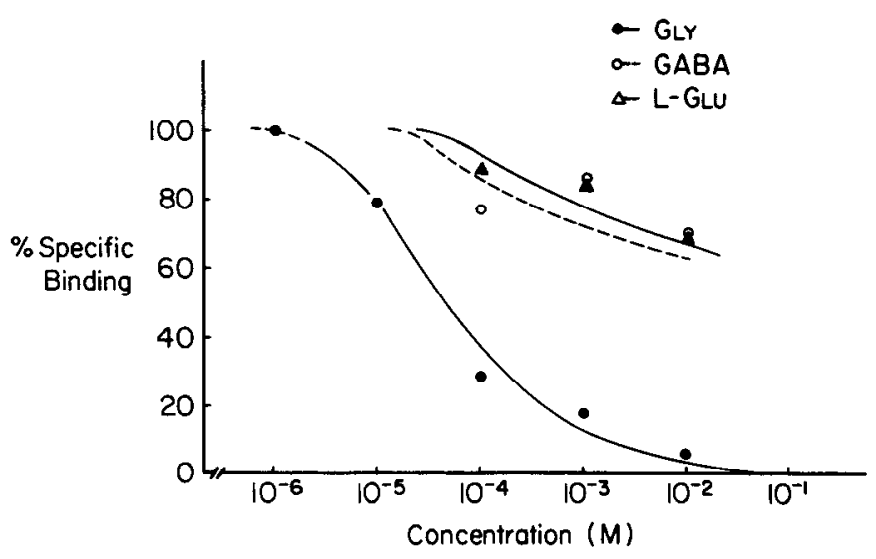

Figure 5. Competition for $10 \mathrm{nM}{ }^{3} \mathrm{H}-\mathrm{SN}$ binding in the brain stem at the level of the superior olivary nuclei. Glycine displaces ${ }^{3} \mathrm{H}-\mathrm{SN}$ at a much lower concentration than either GABA or L-glutamate. 

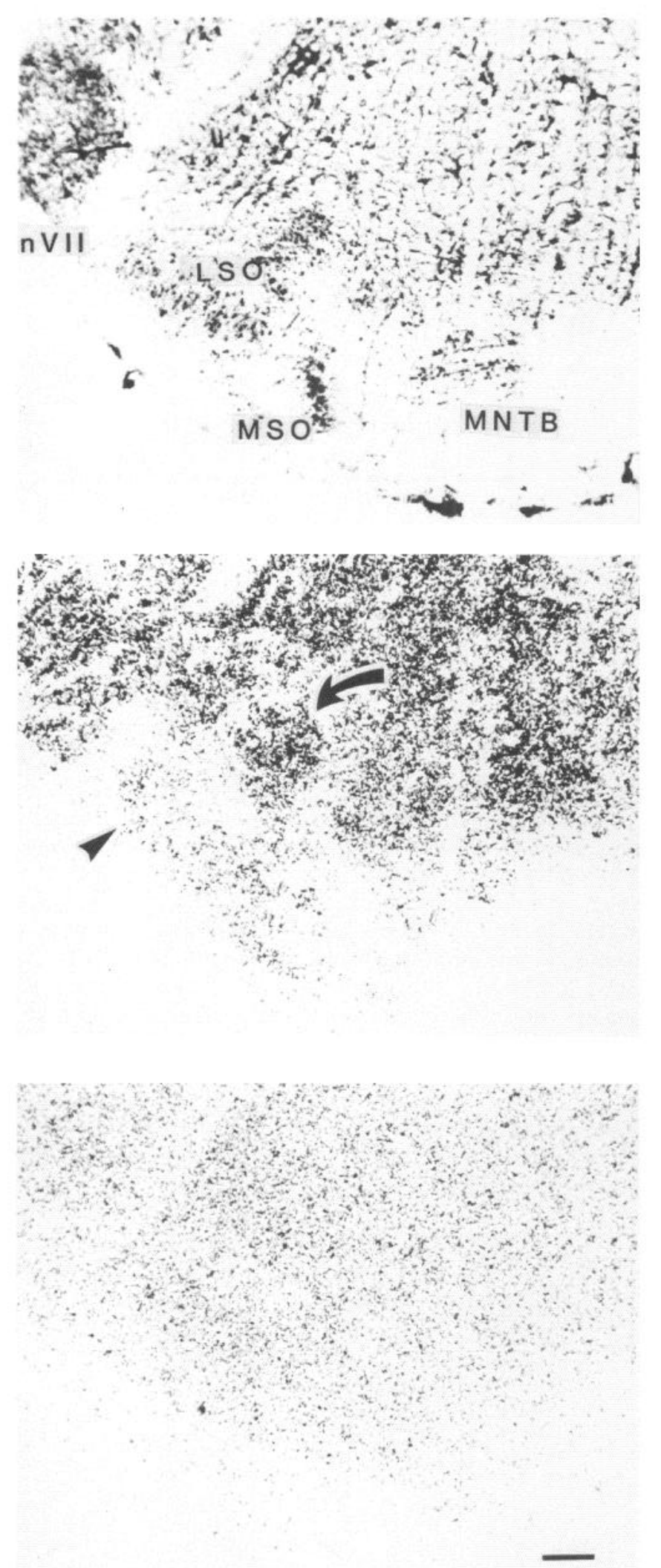

Figure 6. Representative image for ${ }^{3} \mathrm{H}-\mathrm{SN}$ binding distribution in the lateral superior olivary nucleus. The Nissl-stained section (top), autoradiogram of total binding (middle), and autoradiogram of nonspecific binding (bottom) are shown. In the total-binding section, the high-frequency region (arrow) and low-frequency region (arrowhead) of LSO are indicated. It is clear that ${ }^{3} \mathrm{H}-\mathrm{SN}$ binding is relatively greater in the

\begin{tabular}{lcll}
\hline $\begin{array}{l}\text { Table 2. Regional concentration of glycine receptors in several } \\
\text { auditory brain stem nuclei }\end{array}$ & $\begin{array}{l}\text { Glycine receptor } \\
\text { concentration }\end{array}$ & $\begin{array}{l}\text { No. of } \\
\text { animals }\end{array}$ & $\begin{array}{l}\text { No. of } \\
\text { readings }\end{array}$ \\
\hline DCN & $465.5 \pm 73$ & 3 & 110 \\
PVCN & $105 \pm 38$ & 3 & 144 \\
AVCN & $390.4 \pm 19$ & 3 & \\
1 (dorsal) & $232.9 \pm 15$ & & 54 \\
2 & $154.8 \pm 16$ & & 54 \\
3 & & 9 & 54 \\
LSO & $264.4 \pm 46$ & & 166 \\
1 (dorsomedial) & $137.8 \pm 29$ & & 200 \\
2 & $87.0 \pm 26$ & & 136 \\
3 & $61.6 \pm 20$ & & 279 \\
4 & $72.2 \pm 26$ & & 136 \\
5 (ventrolateral) & & 3 & 30 \\
ICC & $76.2 \pm 30$ & 30 \\
1 (dorsal) & $174.2 \pm 11$ & 30 \\
2 & $270.6 \pm 4$ & & \\
3 (ventral) & & & \\
\hline
\end{tabular}

${ }^{a}$ All entries are given in $\mathrm{fmol} / \mathrm{mg}$ wet weight $(\bar{X} \pm \mathrm{SD})$.

that have been carried out (Sanes and Wooten, 1987; Sanes and Rubel, in press). Measurements made along the transverse plane in the dorsal, medial, and ventrolateral aspects of LSO revealed a nonuniform distribution of receptor. There was found to be, on average, an approximately 4 -fold difference in concentration between dorsal and ventrolateral regions (Table 2). No apparent differences in concentration along the rostrocaudal axis were found either for these measurements or using direct visualization of sagittal and horizontal sections (data not shown).

A nonuniform distribution of glycine receptor was, once again, found to exist in the ICC. In this case, the concentration was low dorsally $(76.2 \mathrm{fmol} / \mathrm{mg}$ wet weight) and much greater in the ventral aspect $(270.6 \mathrm{fmol} / \mathrm{mg}$ wet weight). Thus, a 3.5 -fold increase occurred along the dorsoventral axis of ICC. We did not determine whether this was true for the entire rostrocaudal extent of ICC, but rather quantified only sections located within the middle of the nucleus.

\section{Cell density}

The density of neurons was determined within all 3 nuclei that showed a nonuniform distribution of the glycine receptors: AVC, LSO, and ICC. Table 3 shows the cell density measurements obtained for the same 3 regions in each nucleus where receptor concentration was examined. In AVCN there were 1529 neurons $/ \mathrm{mm}^{2}$ dorsally and 676 neurons $/ \mathrm{mm}^{2}$ ventrally, leading to a 2.3-fold difference. Similarly, the LSO exhibited a 2 -fold difference, with the greater density located dorsally. Finally, in the ICC, there was a negligible change in cell density across the dorsoventral axis (Table 3).

\section{Discussion}

The present results are consistent with a role for glycinergic synaptic transmission in the cochlear nucleus, the lateral su-

high-frequency region. $L S O$, Lateral superior olive; $M S O$, medial superior olive; $M N T B$, medical nucleus of the trapezoid body; $n V I I$, facial nerve. Calibration bar, $200 \mu \mathrm{m}$. 


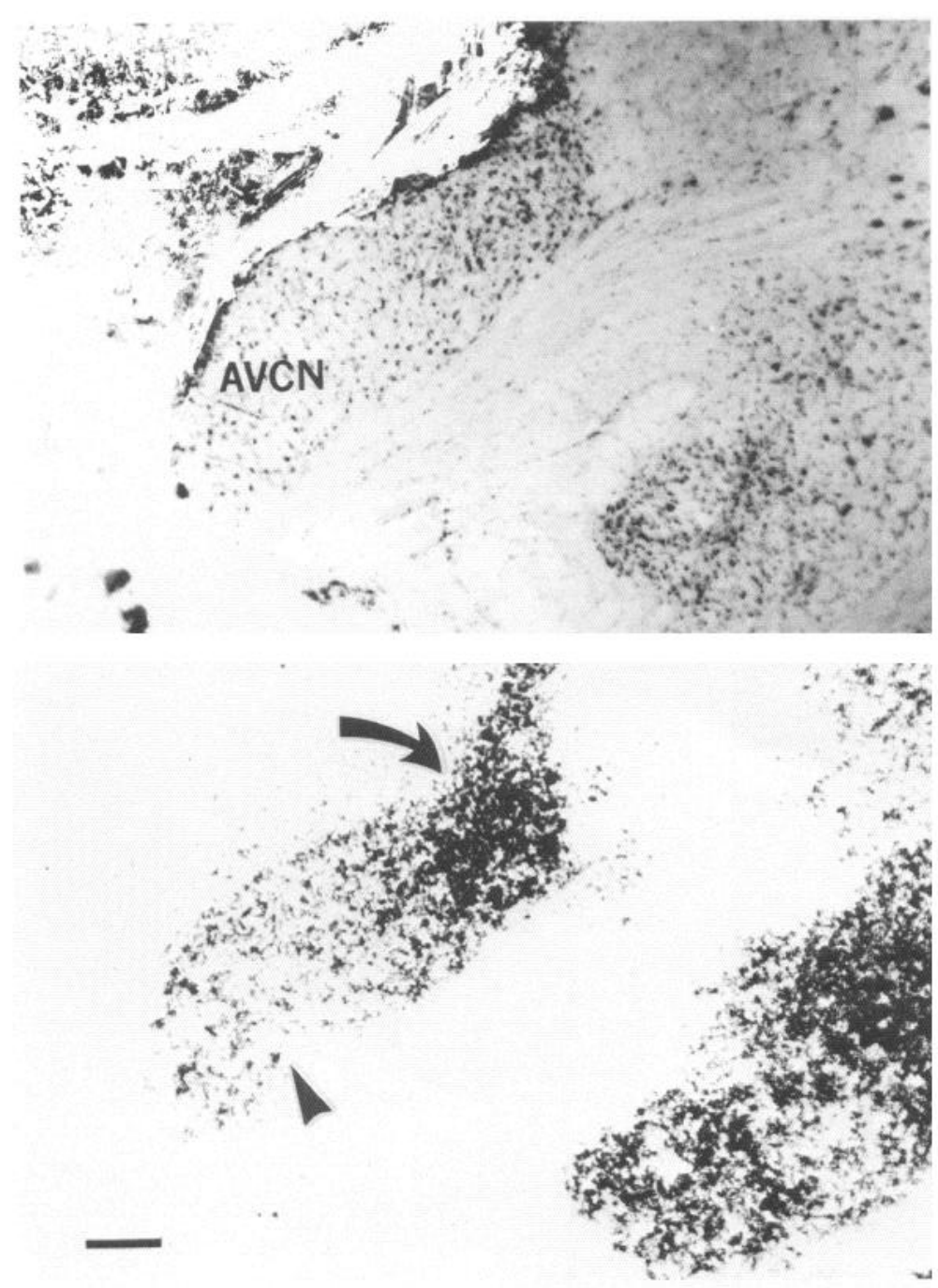

Figure 7. Representative image for ${ }^{3} \mathrm{H}-\mathrm{SN}$ binding distribution in the anteroventral cochlear nucleus. The Nisslstained section (top) and autoradiogram of total binding (bottom) are shown. The high-frequency region ( $a r$ row) and low-frequency region (arrowhead) of AVCN are indicated. ${ }^{3} \mathrm{H}-\mathrm{SN}$ binding is relatively greater in the highfrequency region. $A V C N$, Anteroventral cochlear nucleus. Calibration bar, $200 \mu \mathrm{m}$. perior olivary nucleus, and the inferior colliculus. Previous reports have documented ${ }^{3} \mathrm{H}-\mathrm{SN}$ binding in these and other regions (Zarbin et al., 1981; Frostholm and Rotter, 1985). Furthermore, in at least 3 nuclei, there is a striking nonuniform distribution of ${ }^{3} \mathrm{H}-\mathrm{SN}$ binding in the transverse plane of section. These results are discussed in terms of the known anatomical correlates, the documented tonotopic axes, and functional implications.

The kinetics and pharmacological characteristics of the glycine receptor, as determined in this set of experiments, are comparable to those determined by previous investigators using membrane homogenates (Young and Snyder, 1973) or slidemounted sections (Zarbin et al., 1981). A $K_{d}$ that was calculated to be $15.9-17.9 \mathrm{~nm}$ in the present study was nearly identical to that found for slide-mounted sections in the rat (i.e., 13-15 nM) (Zarbin et al., 1981). The pharmacological specificity of ${ }^{3} \mathrm{H}-\mathrm{SN}$ was also similar to that found in previous studies (Young and Snyder, 1973; Zarbin et al., 1981).

\section{Anatomical correlates to ${ }^{3} \mathrm{H}-\mathrm{SN}$ binding}

The distribution of glycine has been histochemically quantified in the cochlear nuclei of both cat and rat (Godfrey et al., 1977,
Table 3. Regional density of neuronal somas in 3 brain stem auditory nuclei

\begin{tabular}{lcc} 
& Soma density & $\begin{array}{l}\text { No. of } \\
\text { readings } \\
\text { (animals) }\end{array}$ \\
\hline AVCN & \multicolumn{2}{c}{$(3)$} \\
Dorsal & $1529 \pm 75$ & 28 \\
Middle & $889 \pm 128$ & 28 \\
Ventral & $676 \pm 61$ & 28 \\
LSO & $757 \pm 107$ & 31 \\
Dorsal & $597 \pm 153$ & 30 \\
Ventral & $391 \pm 33$ & 36 \\
Ventromedial & $366 \pm 51$ & 34 \\
Ventrolateral & & \multicolumn{2}{c}{$(3)$} \\
ICC & $2041 \pm 82$ & 18 \\
Dorsal & $2132 \pm 26$ & 18 \\
Middle & $2212 \pm 66$ & 18 \\
Ventral & &
\end{tabular}



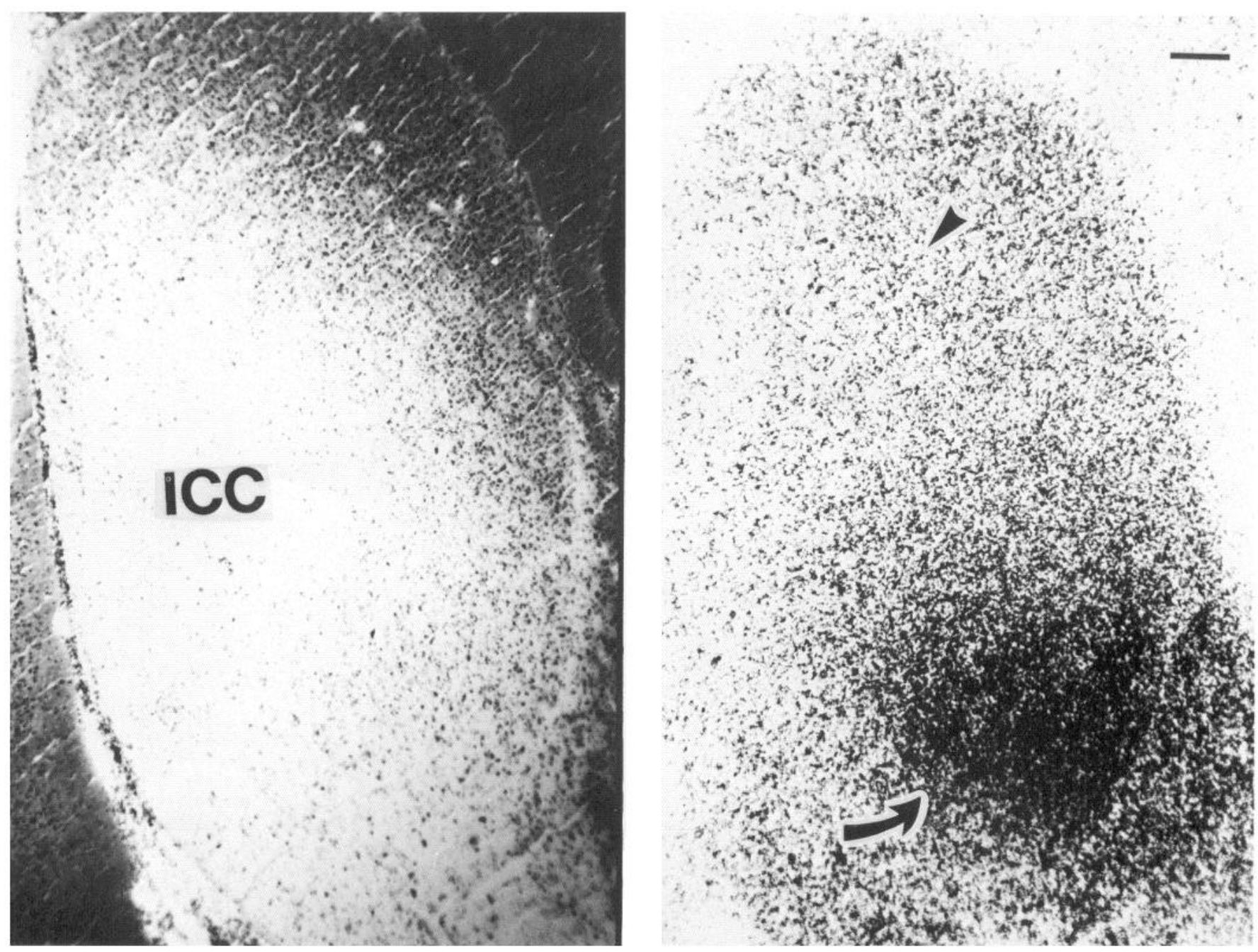

Figure 8. Representative image for ${ }^{3} \mathrm{H}-\mathrm{SN}$ binding distribution in the inferior colliculus. The Nissl-stained section (left) and autoradiogram of total binding (right) are shown. The high-frequency region (arrow) and low-frequency region (arrowhead) of ICC are indicated in the autoradiogram. ${ }^{3} \mathrm{H}-\mathrm{SN}$ binding is relatively greater in the high-frequency region. ICC, Central nucleus of the inferior colliculus. Calibration bar, $200 \mu \mathrm{m}$.

1978). The results correlate well with the present results in that (1) glycine concentration is highest in the DCN, (2) glycine concentration is lowest in the PVCN, and (3) there is a small gradient of glycine concentration in the dorsoventral axis of AVCN. The present findings demonstrate a nonuniform distribution of ${ }^{3} \mathrm{H}-\mathrm{SN}$ binding within AVCN, LSO, and IC. Since the glycinergic inputs presumably mediate inhibition postsynaptically (Curtis et al., 1968), and these synapses are predominantly localized to the somatic region (Cant, 1984; Schwartz, 1985), it was reasonable to estimate the amount of postsynaptic membrane in these nuclei. In 2 cases, the neuron soma density was directly correlated with receptor concentration. In both AVCN and LSO there was an approximately 2 -fold difference along the same axis as was found the glycine receptor gradient. However, the receptor distribution showed a greater difference in both nuclei. There was little, if any, difference in cell soma density across the dorsoventral axis of ICC, whereas a 3.5-fold increase in receptor concentration occurred along that axis. With regard to AVCN, Webster and Trune (1982) have noted a graded distribution of spherical cell soma size from large to small as one moves posteromedially. These authors also point out an apparent difference in spherical cell number along the dorso- ventral axis, as the ascending fibers cause neurons to be more widely spaced ventrally. Nevertheless, the distributions of soma density and receptor concentrations were clearly dissimilar for the LSO and were unrelated for the ICC. Although cell soma packing density is not an inclusive measure of postsynaptic membrane, it appears to offer a partial explanation for our results.

It has been shown by Glendenning et al. (1985) that there is a higher density of terminals from the medial nucleus of the trapezoid body (MNTB) to the medial limb of LSO in the cat. The MNTB is the probable origin of the glycinergic afferent population to LSO (Morest and Jean-Baptiste, 1975; Glendenning et al., 1985; Spangler et al., 1985; Campistron et al., 1986). In addition, the distribution of a monoclonal antibody directed against the glycine receptor shows the same pattern as does ${ }^{3} \mathrm{H}$ $\mathrm{SN}$ within LSO (D. H. Sanes and H. Betz, unpublished observations). There is, at present, no information on the glycinergic afferents to either the cochlear nucleus or the inferior colliculus. At least in the LSO, then, the distribution of postsynaptic receptors appears to be correlated with both the quantity of postsynaptic membrane and the density of terminal arbors from the salient afferent populations. One report of ${ }^{3} \mathrm{H}-\mathrm{SN}$ binding con- 

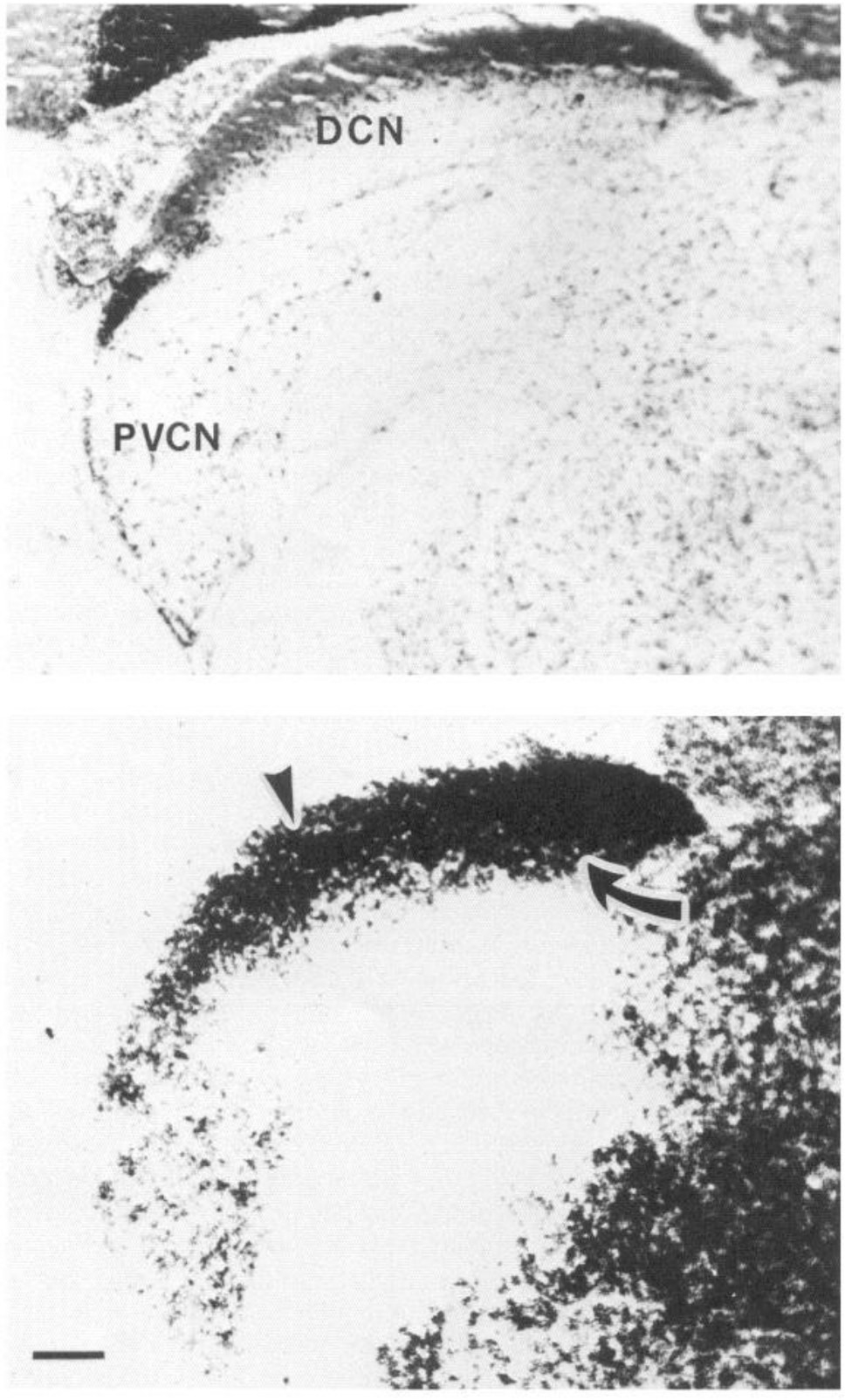

Figure 9. Representative image for ${ }^{3} \mathrm{H}$ $\mathrm{SN}$ binding distribution in the dorsal posteroventral cochlear nuclei. The Nissl-stained section (top) and autoradiogram of total binding (bottom) are shown. The high-frequency region ( $a r$ row) and low-frequency region (arrowhead) of DCN are indicated. No apparent difference in ${ }^{3} \mathrm{H}-\mathrm{SN}$ binding was observed across the frequency axis. $D C N$, Dorsal cochlear nucleus; $P V C N$, posteroventral cochlear nucleus. Calibration bar, $200 \mu \mathrm{m}$ tains an autoradiographic image of ICC that has a similar, nonuniform distribution, although there appears to be no receptor gradient in the LSO (Frostholm and Rotter, 1985).

Unfortunately, these data do not resolve the issue of whether or not there are a greater number of receptors per postsynaptic area in those nuclear regions with higher ${ }^{3} \mathrm{H}-\mathrm{SN}$ binding site concentration. Three viable alternatives are that (1) there are a greater number of neurons in a particular region of each nucleus, (2) there is a greater amount of membrane per neuron (e.g., dendrite) in a particular region of each nucleus, and (3) there are ${ }^{3} \mathrm{H}-\mathrm{SN}$ binding sites that are not located postsynaptically that show a nonuniform distribution. The first alternative is implausible for the inferior colliculus. Moreover, there is no indication from any of the available Golgi studies (Rockel and Jones, 1973; Scheibel and Scheibel, 1974; Ollo and Schwartz, 1979; Webster and Trune, 1982; Cant, 1984; Helfert and Schwartz, 1986) that postsynaptic membrane is dramatically enhanced in any region of AVCN, LSO, or ICC. It should be noted, however, that such a dendritic pattern has been found for an auditory nucleus in the chicken brain stem (Smith and Rubel, 1979).

\section{Tonotopic axes}

A common property of central auditory nuclei is the sequential representation of frequency along one axis, the tonotopic organization (see Clopton et al., 1974). This characteristic has been well-documented for each of the nuclei in which nonuniform ${ }^{3} \mathrm{H}-\mathrm{SN}$ binding occurred, thus allowing for comparison.

The anatomical projection of the eighth nerve suggests (Webster, 1971; Fekete et al., 1984), and electrophysiological studies confirm (Rose et al., 1959; Evans, 1975; Ryan et al., 1982), that there is a tonotopic organization of high to low frequencies from dorsal to ventral in the $\mathrm{AVCN}$ and PVCN, and from dorsomedial to ventrolateral in the DCN. The distribution of ${ }^{3} \mathrm{H}-\mathrm{SN}$ binding is, therefore, found along the tonotopic axis of AVCN such that the high-frequency region (i.e., dorsal) has the greatest 
concentration of receptor. Since the tonotopic axes of PVCN and DCN are also represented in the transverse plane, a failure to find a gradient of ${ }^{3} \mathrm{H}-\mathrm{SN}$ binding indicates that one does not exist or is to be found along an oblique axis.

The tonotopic axis has been determined within the LSO of 2 species, the cat and gerbil (Tsuchitani and Boudreau, 1966; Ryan et al., 1982; D. H. Sanes, M. Merickel, and E. W Rubel, unpublished observations). The frequency map progresses from high to low as one moves from the dorsomedial region to the ventrolateral region. The observed ${ }^{3} \mathrm{H}-\mathrm{SN}$ binding distribution shows an approximately 4-fold difference across the same axis, such that the high-frequency region (i.e., dorsomedial) is the site of greatest binding.

The tonotopic axis of the ICC has been well-established by electrophysiological and metabolic analyses (Rose et al., 1959; Semple and Aitkin, 1979; Ryan et al., 1982; Melzer, 1984; Stiebler and Ehret, 1985; Huang and Fex, 1986). In the central nucleus of all species examined, the map progresses from low to high frequency as one moves from dorsal to ventral. The ${ }^{3} \mathrm{H}$ SN binding distribution is, once again, found along the tonotopic axis, such that high-frequency regions exhibit the greatest binding.

The 3 nuclei that are found to have a nonuniform distribution of glycine receptors (AVCN, LSO, and ICC) show similar characteristics in that the phenomenon occurs across the tonotopic axis, and the greatest concentration of receptor is localized to the high-frequency region. For 2 subdivisions of the cochlear nucleus (PVCN and DCN) there is no apparent gradient of receptor along the frequency axis. Since the known anatomical correlates, including neuron packing density, do not account for the entirety of these results, it is worthwhile considering their potential functional implications, especially with regard to inhibition.

\section{Functional implications}

The 3 major divisions of the cochlear nucleus are known to differ in their responses to sound stimuli (Rose et al., 1959; Pfeiffer, 1966; Evans and Nelson, 1973; Godfrey et al., 1975a, b; Britt and Starr, 1976). The AVCN, for example, appears to preserve the coding properties of the eighth nerve fibers (Pfeiffer, 1966; Rhode et al., 1983b). It is known that some neurons in the rostral two-thirds of AVCN obtain inhibitory sidebands, such that frequencies that are greater and less than those exciting the cell will actively inhibit it (Martin and Dickson, 1983). Although the afferent population and transmitter system mediating this inhibition are unknown, the present results allow for the possibility that glycinergic terminals are involved. Recently, Wu and Oertel (1986) demonstrated that strychnine blocks inhibitory potentials in the mouse VCN.

The coding properties of the DCN are far more complex and include a preponderance of inhibitory interaction (Greenwood and Maruyama, 1965; Caspary, 1972; Evans and Nelson, 1973; Goldberg and Brownell, 1973; Britt and Starr, 1976; Voigt and Young, 1980; Rhode et al., 1983a). It is not surprising that ${ }^{3} \mathrm{H}$ SN binding is greatest in this auditory region, as is the concentration of glycine (Godfrey et al., 1977, 1978). Preliminary iontophoretic results indicate that glycine is a potent inhibitor of tone-evoked activity in the DCN (Caspary et al., 1985). Therefore, glycine is certainly a candidate in mediating the proposcd inhibition of the principal neurons in DCN (i.e., type IV) by a class of interneurons (Voigt and Young, 1980; Young, 1980).

Neurons in the LSO are fairly homogenous in their coding properties, being excited by ipsilaterally presented sound and inhibited by contralaterally presented sound (Boudreau and Tsuchitani, 1968, 1970; Caird and Klinke, 1983; Harnischfeger et al., 1985; Sanes and Rubel, in press). The present results are consistent with those obtained from iontophoretic experiments in the LSO of chinchilla (Moore and Caspary, 1983). It was shown that glycine suppresses the ipsilaterally evoked response, whereas strychnine blocks the contralaterally elicited inhibition. Since GABA was found to be effective in suppressing activity in a few neurons, an exclusive role for glycinergic transmission is unlikely.

There are, at present, no published physiological results that can be correlated with the nonuniformity of ${ }^{3} \mathrm{H}-\mathrm{SN}$ binding within LSO. However, we have recorded from single units in the gerbil LSO (Sanes and Rubel, in press) and found that inhibition is somewhat more efficacious in high-frequency regions (i.e., dorsomedial) than in low-frequency regions (i.e., ventrolateral). This finding lends support to the idea that the ${ }^{3} \mathrm{H}-\mathrm{SN}$ binding gradient represents a functional difference along the tonotopic axis of the LSO. More speculatively, such a functional difference across the frequency axis may be correlated with the distinct projection patterns of the high- and low-frequency LSO regions (Glendenning and Masterton, 1983).

The ICC responds to both interaural time differences and interaural intensity differences, the latter involving inhibitory interactions (Erulkar, 1959; Hind et al., 1963; Nelson and Erulkar, 1963; Rose et al., 1963, 1966; Knudsen and Konishi, 1978; Kuwada and Yin, 1983; Webster et al., 1984). There are also known to be inhibitory sidebands, which may serve to sharpen the frequency tuning of these neurons (Willott and Urban, 1978). Glycine causes a depression of tone-evoked activity (Watanabe and Simada, 1973). Although a glycinergic synapse could, in principle, serve either function, this would not explain the nonuniform distribution of ${ }^{3} \mathrm{H}-\mathrm{SN}$ binding in the ICC.

Wenstrup et al. (1985) have recently demonstrated a functional gradient of inhibition within the ICC of the bat. Neurons within an isofrequency contour are found to have lower inhibitory thresholds the more ventrally they are located. Given the great amount of cochlear and neural space devoted to a small frequency range in the bat (see Bruns, 1979), it is conceivable that such a gradient of inhibition may exist across isofrequency contours in other species. Even within the bat, it has been found that inhibitory sidebands are more prominent for the higherfrequency neurons in the auditory cortex (Suga and Tsuzuki, 1985).

In explaining nonuniform ${ }^{3} \mathrm{H}-\mathrm{SN}$ binding, the alternative to functional significance is anatomical constraint. Both the mouse and rat are known to have an increasing density of hair cells progressing towards the midbasal or basal region of the cochlea, respectively (Ehret and Frankenreiter, 1977; Burda and Voldrich, 1980). A corresponding increase in the number of cochlear afferents has been documented for that region of the mousc cochlea having the greatest hair cell density (Ehret, 1979). One resolution to the present results, then, might obtain if there were a consistent increase in the density of higher-frequency elements from the cochlea throughout the central auditory system. As has been noted above, this does not appear to be true at the level of the ICC, since neuron density does not change along the tonotopic axis.

In summary, we have used quantitative autoradiographic methods (Geary et al., 1985) to determine the concentration of glycine receptors in several brain stem auditory structures. The 
preponderance of receptor in these nuclei correlated well with the known levels of inhibitory function and, in the case of the cochlear nucleus, the levels of glycine (Godfrey et al., 1977, 1978). In AVCN, LSO, and ICC there was a nonuniform distribution of binding that was aligned with the known tonotopic axes. In each case, high-frequency regions had the greatest concentration of receptor.

\section{References}

Boudreau, J. C., and C. Tsuchitani (1968) Binaural interaction in the cat superior olive S-segment. J. Neurophysiol. 31: 442-454.

Boudreau, J. C., and C. Tsuchitani (1970) Cat superior olive S-segment cell discharge to tonal stimuli. In Contributions to Sensory Physiology, D. Neff, ed., pp. 143-213, Academic, New York.

Britt, R., and A. Starr (1976) Synaptic events and discharge patterns of cochlear nucleus cells. I. Steady frequency tone bursts. J. Neurophysiol. 39: 162-178.

Bruns, V. (1979) Functional anatomy as an approach to frequency analysis in the mammalian cochlea. Verh. Dtsch. Ges. Zool. 1979: 141-154.

Burda, H., and L. Voldrich (1980) Correlation between the hair cell density and the auditory threshold in the white rat. Hear. Res. 3:9193.

Caird, D., and R. Klinke (1983) Processing of binaural stimuli by cat superior olivary complex neurons. Exp. Brain Res. 52: 385-399.

Campistron, G., R. Buijs, and M. Geffard (1986) Glycine neurons in brain and spinal cord. Antibody production and immunocytochemical localization. Brain Res. 376: 400-405.

Cant, N. B. (1984) The fine structure of the lateral superior olivary nucleus of the cat. J. Comp. Neurol. 227: 63-77.

Caspary, D. M. (1972) Classification of subpopulations of neurons in the cochlear nuclei of the kangaroo rat. Exp. Neurol. 37: 131-151.

Caspary, D. M., L. P. Rybak, and C. L. Faingold (1985) The effects of inhibitory and excitatory amino-acid neurotransmitters on the response properties of brain stem auditory neurons. In Auditory Biochemistry, D. G. Drescher, ed., pp. 198-226, Thomas, Springfield, MA.

Clopton, B. M., J. A. Winfield, and F. J. Flammino (1974) Tonotopic organization: Review and analysis. Brain Res. 76: 1-20.

Curtis, D. R., L. Hosli, G. A. R. Johnston, and I. H. Johnston (1968) The hyperpolarization of spinal motoneurons by glycine and related amino acids. Exp. Brain Res. 5: 235-258.

Curtis, D. R., A. W. Duggan, and G. A. R. Johnston (1971) The specificity of strychnine as a glycine antagonist in the mammalian spinal cord. Exp. Brain Res. 12: 547-565.

Ehret, G. (1979) Quantitative analysis of nerve fibre densities in the cochlea of the house mouse. J. Comp. Neurol. 183: 73-88.

Ehret, G., and M. Frankenreiter (1977) Quantitative analysis of cochlear structures in the house mouse in relation to mechanisms of acoustical information processing. J. Comp. Physiol. 122: 65-85.

Erulkar, S. D. (1959) The responses of single units of the inferior colliculus of the cat to acoustic stimulation. Proc. R. Soc. Lond. [Biol.] 150: 336-355.

Evans, E. F. (1975) Cochlear nerve and cochlear nucleus. In Handbook of Sensory Physiology, vol. 5, pt. 2, W. D. Keidel and W. D. Neff, eds., pp. 1-108, Springer, Berlin.

Evans, E. F., and P. G. Nelson (1973) The responses of single neurones in the cochlear nucleus of the cat as a function of their location and anaesthetic state. Exp. Brain Res. 17: 402-427.

Fekete, D. M., E. M. Rouiller, M. C. Liberman, and D. K. Ryugo (1984) The central projections of intracellularly labeled auditory nerve fibers in cats. J. Comp. Neurol. 229: 432-450.

Frostholm, A., and A. Rotter (1985) Glycine receptor distribution in mouse CNS: Autoradiographic localization of $\left[{ }^{3} \mathrm{H}\right]$ strychnine binding sites. Brain Res. Bull. 15: 473-486.

Geary, W. A., A. W. Toga, and G. F. Wooten (1985) Quantitative film autoradiography for tritium: Methodological considerations. Brain Res. 337: 99-108.

Glendenning, K. K., and R. B. Masterton (1983) Acoustic chiasm: Efferent projections of the lateral superior olive. J. Neurosci. 3: 15211537.

Glendenning, K. K., K. A. Hutson, R. J. Nudo, and R. B. Masterton
(1985) Acoustic chiasm Il: Anatomical basis of binaurality in lateral superior olive of cal. J. Comp. Neurol. 232: 261-285.

Godfrey, D. A., N. Y.-S. Kiang, and B. E. Norris (1975a) Single unit activity in the posteroventral cochlear nucleus of the cat. J. Comp. Neurol. 162: 247-268.

Godfrey, D. A., N. Y.-S. Kiang, and B. E. Norris (1975b) Single unit activity in the dorsal cochlear nucleus of the cat. J. Comp. Neurol. 162: 269-289.

Godfrey, D. A., J. A. Carter, S. J. Berger, O. H. Lowry, and F. M. Matschinsky (1977) Quantitative histochemical mapping of candidate transmitter amino acids in cat cochlear nucleus. J. Histochem. Cytochem. 25: 417-431.

Godfrey, D. A., J. A. Carter, O. H. Lowry, and F. M. Matschinsky (1978) Distribution of GABA-aminobutyric acid, glycine, glutamate and aspartate in the cochlear nucleus of the rat. J. Histochem. Cytochem. 26: 188-126.

Goldberg, J. M., and W. E. Brownell (1973) Response characteristics of neurons in anteroventral and dorsal cochlear nuclei of cat. Brain Res. 64: 35-54.

Greenwood, D. D., and N. Maruyama (1965) Excitatory and inhibitory reponse areas of auditory neurons in the cochlear nucleus. $J$. Neurophysiol. 28: 863-892.

Harnischfeger, G., G. Neuweiler, and P. Schlegel (1985) Interaural time and intensity coding in superior olivary complex and inferior colliculus of the echolocating bat Molossus ater. J. Neurophysiol. 53: 89-109.

Helfert, R. H., and I. R. Schwartz (1986) Morphological evidence for the existence of multiple neuronal classes in the cat lateral superior olivary nucleus. J. Comp. Neurol. 244: 533-549.

Hind, J. E., J. M. Goldberg, D. D. Greenwood, and J. E. Rose (1963) Some discharge characteristics of single neurons in the inferior colliculus of the cat. II. Timing of the discharges and observations on binaural stimulation. J. Neurophysiol. 26: 321-341.

Hosli, E., and L. Hosli (1981) Binding of $\left[{ }^{3} \mathrm{H}\right]$ glycine, $\left[{ }^{3} \mathrm{H}\right] \beta$-alanine and $\left[{ }^{3} \mathrm{H}\right]$ strychnine in cultured rat spinal cord and brain stem. Brain Res. 213: 242-245.

Huang, C. -M., and J. Fex (1986) Tonotopic organization in the inferior colliculus of the rat demonstrated with the 2-deoxyglucose method. Exp. Brain Res. 61: 506-512.

Knudsen, E. I., and M. Konishi (1978) Center-surround organization of auditory receptive fields in the owl. Science 202: 778-780.

Kuwada, S., and T. C. T. Yin (1983) Binaural interaction in lowfrequency neurons in inferior colliculus of the cat. I. Effects of long interaural delays, intensity, and repetition rate on interaural delay function. J. Neurophysiol. 50: 981-999.

Martin, M. R., and J. W. Dickson (1983) Lateral inhibition in the anteroventral cochlear nucleus of the cat: A microiontophoretic study. Hear. Res. 9: 35-41.

Melzer, P. (1984) The central auditory pathway of the gerbil Psammomys obesus: A deoxyglucose study. Hear. Res. 15: 187-195.

Moore, M. J., and D. M. Caspary (1983) Strychnine blocks binaural inhibition in lateral superior olivary neurons. J. Neurosci. 3: 237247.

Morest, D. K., and M. Jean-Baptiste (1975) Degeneration and phagocytosis of synaptic endings and axons in the medial trapezoid nucleus of the cat. J. Comp. Neurol. 162: 135-156.

Nelson, P. G., and S. D. Erulkar (1963) Synaptic mechanisms of excitation and inhibition in the central auditory pathway. J. Neurophysiol. 26: 908-923.

Ollo, C., and I. Schwartz (1979) The superior olivary complex in C57BL/6 mice. Am. J. Anat. 155: 349-374.

Pfeiffer, F., and H. Betz (1981) Solubilization of the glycine receptor from rat spinal cord. Brain Res. 226: 273-279.

Pfeiffer, F., D. Graham, and H. Betz (1982) Purification by affinity chromatography of the glycine receptor of rat spinal cord. J. Biol. Chcm. 257: 9389-9393.

Pfeiffer, R. R. (1966) Classification of response patterns of spike discharges for units in the cochlear nucleus: Tone-burst stimulation. Exp. Brain Res. 1: 220-235.

Rhode, W. S., P. H. Smith, and D. Oertel (1983a) Physiological response properties of cells labeled intracellularly with horseradish peroxidase in cat dorsal cochlear nucleus. J. Comp. Neurol. 213: 426447.

Rhode, W. S., D. Oertel, and P. H. Smith (1983b) Physiological response properties of cells labeled intracellularly with horseradish per- 
oxidase in cat ventral cochlear nucleus. J. Comp. Neurol. 213: 448463.

Rockel, A. J., and E. G. Jones (1973) The neuronal organization of the inferior colliculus of the adult cat. I. The central nucleus. J. Comp. Neurol. 147: 11-60.

Rose, J. E., R. Galambos, and J. R. Hughes (1959) Microelectrode studies of the cochlear nuclei of the cat. Johns Hopkins Med. J. 104: $211-251$

Rose, J. E., D. D. Greenwood, J. M. Goldberg, and J. E. Hind (1963) Some discharge characteristics of single neurons in the inferior colliculus of the cat. I. Tonotopic organization, relation of spike-counts to tone intensity and firing patterns of single elements. J. Neurophysiol. 26: 294-320.

Rose, J. E., N. B. Gross, C. D. Geisler, and J. E. Hind (1966) Some neural mechanisms in the inferior colliculus of the cat which may be relevant to localization of a sound source. J. Neurophysiol. 29: 288314.

Ryan, A. F., N. K. Woolf, and F. R. Sharp (1982) Tonotopic organization in the central auditory pathway of the Mongolian gerbil: A 2-deoxyglucose study. J. Comp. Neurol. 207: 369-380.

Sanes, D. H., and E. W. Rubel, (in press) The ontogeny of inhibition and excitation in the gerbil lateral superior olive. J. Neurosci.

Sanes, D. H., and G. F. Wooten (1987) Development of glycine receptor distribution in the lateral superior olive of the gerbil. $J$. Neurosci. 7: 3803-3811.

Scheibel, M. E., and A. B. Scheibel (1974) Neuropil organization in the superior olive of the cat. Exp. Neurol. 43: 339-348.

Schwartz, 1. (1985) Autoradiographic studies of amino acid labeling of neural elements in the auditory brain stem. In Auditory Biochemistry, D. G. Drescher, ed., pp. 258-277, Thomas, Springfield, MA.

Semple, M. N., and L. M. Aitkin (1979) Representation of sound frequency and laterality by units in central nucleus of cat inferior colliculus. J. Neurophysiol. 42: 1626-1639.

Smith, D. J., and E. W. Rubel (1979) Organization and development of brain stem auditory nuclei of the chicken: Dendritic gradients in nucleus laminaris. J. Comp. Neurol. 186: 213-240.

Snyder, S. H. (1975) The glycine synaptic receptor in the mammalian central nervous system. Br. J. Pharmacol. 53: 473-484.

Spangler, K. M., W. B. Warr, and C. K. Henkel (1985) The projections of the principal cells of the medial nucleus of the trapezoid body in the cat. J. Comp. Neurol. 238: 249-262.

Stiebler, I., and G. Ehret (1985) Inferior colliculus of the house mouse. I. A. quantitative study of tonotopic organization, frequency representation, and tone-threshold distribution. J. Comp. Neurol. 238: $65-76$.
Suga, N., and K. Tsuzuki (1985) Inhibition and level tolerant frequency tuning in the auditory cortex of the mustached bat. J. Neurophysiol. 53: 1109-1145.

Triller, A., F. Cluzeaud, F. Pfeiffer, H. Betz, and H. Korn (1985) Distribution of glycine receptors at central synapses: An immunoelectron microscopy study. J. Cell Biol. 101: 683-688.

Tsuchitani, C., and J. C. Boudreau (1966) Single unit analysis of cat superior olivary complex. J. Neurophysiol. 40: 296-318.

Voigt, H. F., and E. D. Young (1980) Evidence of inhibitory interactions between neurons in the dorsal cochlear nucleus. J. Neurophysiol. 44: 76-96.

Watanabe, T., and Z. Simada (1973) Pharmacological properties of cat's collicular auditory ncurons. Jpn. J. Physiol. 23: 291-308.

Webster, D. B. (1971) Projection of the cochlea to cochlear nuclei in Merriam's kangaroo rat. J. Comp. Neurol. 143: 323-340.

Webster, D. B., and D. R. Trune (1982) Cochlear nuclear complex of mice. Am. J. Anat. 163: 103-130.

Webster, W. R., J. Serviere, and M. Brown (1984) Inhibitory contours in the inferior colliculus as revealed by the 2-deoxyglucose method. Exp. Brain Res. 56: 577-581.

Wenstrup, J. J., L. S. Ross, and G. D. Pollak (1985) A functional organization of binaural responses in the inferior colliculus. Hear. Res. 17: 191-195.

Wenthold, R. J., H. Betz, K. A. Reeks, M. H. Parakkal, and R. A. Altschuler (1985) Localization of glycinergic synapses in the cochlear nucleus and superior olivary complex with monoclonal antibodies specific for the glycinc receptor. Soc. Neurosci. Abstr. 11: 1048.

Willott, J. F., and G. P. Urban (1978) Response properties of neurons in nuclei of the mouse inferior colliculus. J. Comp. Physiol. 127:175184.

$\mathrm{Wu}, \mathrm{S}$. H., and D. Oertel (1986) Inhibitory circuitry in the ventral cochlear nucleus is probably mediated by glycine. J. Neurosci. 6 : 2691-2706.

Young, A. B., and S. H. Snyder (1973) Strychnine binding associated with glycine receptors of the central nervous system. Proc. Natl. Acad. Sci. USA 70: 2832-2836.

Young, E. D. (1980) Identification of response properties of ascending axons from dorsal cochlear nucleus. Brain Res. 200: 23-37.

Zarbin, M. A., J. K. Wamsley, and M. J. Kuhar (1981) Glycine receptor: Light microscopic autoradiographic localization with $\left[{ }^{3} \mathrm{H}\right]-$ strychnine. J. Neurosci. 1: 532-547.

Zivin, J. A., and D. R. Waud (1982) How to analyze binding, enzyme, and uptake data: The simplest case, a single phase. Life Sci. 30: 14071422 . 